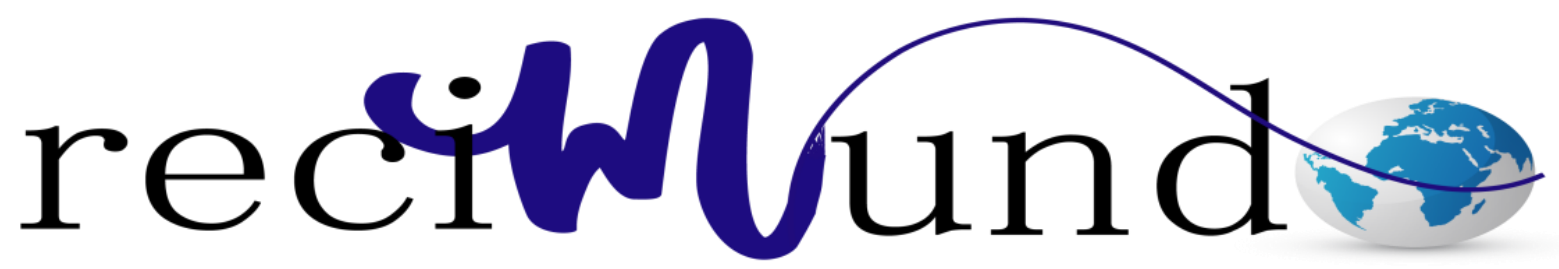

Revista Científica Mundo de la Investigación y el Conocimiento

Venus Alexandra Rodríguez-Matías ${ }^{\text {a }}$; Carlos Alfredo Lozano-Rodríguez ${ }^{\text {; }}$ L Luis Alberto Rodríguez-Matías ${ }^{c}$; Roberto Jairo Tuesca Armijos ${ }^{\text {d }}$

El VPH: Enemigo silencioso de los millennials

HPV: Silent Enemy of the Millennials

Revista Científica Mundo de la Investigación y el Conocimiento. Vol. 2 núm.3, julio, ISSN: 2588-073X, 2018, pp. 393-405

DOI: 10.26820/recimundo/2.(3).julio.2018.393-409

Editorial Saberes del Conocimiento

Recibido: 05/04/2018

Aceptado: 03/06/2018

Publicado: 30/07/2018

Correspondencia: venus aroma@hotmail.com
a. Médico; venus_aroma@hotmail.com
b. Médico; carloz 83@ hotmail.com
c. Especialista en Ginecologia y Obstetricia; Médico; larm1978@ outlook.com
d. Médico; mustangstrife@ gmail.com 


\section{EI VPH: Enemigo silencioso de los millennials}

Vol. 2, núm. 3., (2018)

Venus Alexandra Rodríguez-Matías; Carlos Alfredo Lozano-Rodríguez; Luis Alberto Rodríguez-Matías; Roberto Jairo Tuesca Armijos

\section{RESUMEN}

El comportamiento de los individuos está basado en la formación otorgada por la familia y la sociedad. Esta sociedad influye directamente sobre las conductas sexuales de las personas y más de aquellas que son más vulnerables, los jóvenes. En etapa temprana se tiene una desvinculación entre las relaciones románticas y las relaciones sexuales donde ambas son volátiles ya que hay mayor cambio de parejas e inestabilidad de las mismas. Todo esto lleva a que sean más propensos a sufrir enfermedades de transmisión sexual. Entre esas enfermedades se encuentra en VPH, la cual es muy común pero que lamentablemente no se ha atacado desde diferentes perspectivas. Esta investigación tiene como objetivo analizar el VPH como enfermedad de transmisión sexual a los jóvenes menores de 25 años. La parte metodológica se basó en la comprensión de la familia y la sociedad como factor predominante en el comportamiento del individuo, relacionar las ETS, y sobre todo el VPH, con la relación sexual precoz y por último en la prevención de esta enfermedad. Como conclusión se obtuvo que las personas que tienen relaciones sexuales tempranas son más propensas a sufrir VPH y que la falta de información, desde cualquier arista, incrementa el riesgo de contraer el virus.

Palabras claves: Familia, sociedad, relaciones sexuales, VPH, millennials. 
EI VPH: Enemigo silencioso de los millennials

Vol. 2, núm. 3., (2018)

Venus Alexandra Rodríguez-Matías; Carlos Alfredo Lozano-Rodríguez; Luis Alberto

Rodríguez-Matías; Roberto Jairo Tuesca Armijos

\begin{abstract}
The behavior of individuals is based on the training provided by the family and society. This society directly influences the sexual behavior of people and more of those who are more vulnerable, young people.In early stage there is a separation between romantic relationships and sexual relations where both are volatile as there is a greater change of partners and their instability. All this leads to their being more prone to suffer from sexually transmitted diseases.Among those diseases is HPV, which is very common but unfortunately has not been attacked from different perspectives. This research aims to analyze HPV as a sexually transmitted disease to young people under 25 years of age.The methodological part was based on the understanding of family and society as a predominant factor in the behavior of the individual, relating STDs, and especially HPV, with early sexual intercourse and finally in the prevention of this disease.As a conclusion it was obtained that people who have early sexual relations are more prone to suffer HPV and that the lack of information, from any edge, increases the risk of contracting the virus.
\end{abstract}

Keywords: Family, society, sexual relations, HPV, millennials. 


\section{EI VPH: Enemigo silencioso de los millennials}

Vol. 2, núm. 3., (2018)

Venus Alexandra Rodríguez-Matías; Carlos Alfredo Lozano-Rodríguez; Luis Alberto Rodríguez-Matías; Roberto Jairo Tuesca Armijos

\section{Introducción.}

En los últimos tiempos, todo lo que tiene que ver con la sexualidad se ha explotado en su máxima expresión. Manifestaciones que demuestran la proliferación de las tendencias sexuales se han convertido en un derecho innegable de las personas. Expresar sus sentimientos hacia estos temas es importante y resalta el carácter del individuo actual. Ya temas que se consideran mitos son temas comunes y frecuentes entre la sociedad. La comunidad de feministas, LGTB y comunidades que aprueban el aborto se ven en cada esquina de las calles. Todo esto se demuestra en este tiempo, el tiempo de los millennials es un tiempo de liberación, un tiempo de irreverentes, pero sobre todo un tiempo de expresar todo lo que pasa por las mentes sin medir tapujos o creencias. Es el derecho de respetar las opiniones y creer en ellas.

Lamentablemente en las calles no se observan, comparadas con las manifestaciones culturales, políticas y libertad de género, las manifestaciones sobre enfermedades sexuales. Las pocas manifestaciones que ocurren son por la principal enfermedad de transmisión sexual que es en VIH. No existen manifestaciones a favor de ciertas vacunas contra estos males y se consideran que estos temas siguen siendo tabú en nuestra sociedad. Las personas no pueden enfrentar esta problemática porque es enfrentarse ante un muro que cierra todas posibilidades de poder liberarse sexualmente. Conocen que un aspecto negativo de esa liberación sexual es el contraer enfermedades. Estas enfermedades nacen en la década de los 80’s como respuesta a la liberación de la sexualidad en todos los géneros, afectando principalmente a la comunidad gay, pero en la medida del tiempo afectando a cualquier persona sin importar si fue por transmisión sexual. 


\section{EI VPH: Enemigo silencioso de los millennials}

Vol. 2, núm. 3., (2018)

Venus Alexandra Rodríguez-Matías; Carlos Alfredo Lozano-Rodríguez; Luis Alberto Rodríguez-Matías; Roberto Jairo Tuesca Armijos

El virus del papiloma humano es una enfermedad de transmisión sexual y se caracteriza por la formación de un crecimiento benigno, verruga, o papiloma, ubicado en cualquier lugar del cuerpo (Concha, 2007) y es una de las principales causas del cáncer del cuello uterino. La promiscuidad constituye un importante factor de riesgo para este tipo de cáncer. Numerosos mecanismos han sido sugeridos para explicar la relación entre el riesgo de padecer la enfermedad y los diversos elementos asociados con las relaciones sexuales, entre ellos la edad del comienzo de las relaciones sexuales y la transmisión de agentes infecciosos (León y Bosques, 2018).

Es allí que radica la importancia de una buena educación sexual a temprana edad porque los principales afectados son los adolescentes que no tienen una buena formación sobre sexualidad. Es difícil este paso educativo y más cuando el primer paso debe ser en casa. La gran mayoría de los padres consideran la sexualidad como tabú y por ende no afrontan estas situaciones como prioritarias. Por miedo o por estar sujetos a las opiniones de la sociedad, estos temas son pocos abordados, pero ya es hora de que toman un lugar protagónico en los hogares. La enfermedad ataca principalmente en edades tempranas y por el no conocimiento se infecta este virus.

Desde las escuelas, colegios y universidades se abordan estos temas porque pertenecen a las mallas curriculares, pero no están enfocadas o conectadas con la persona, sino que engloban términos generales a las cuales los individuos no se sienten familiarizados sino más bien es una obligación conocerlo porque se trata de una calificación o una asignación académica. Es necesario, desde casa y desde la escuela, atacar este problema, pero hacerlo más humano, más personal, que tenga un poco más de contacto con los sentimientos del individuo. 


\section{EI VPH: Enemigo silencioso de los millennials}

Vol. 2, núm. 3., (2018)

Venus Alexandra Rodríguez-Matías; Carlos Alfredo Lozano-Rodríguez; Luis Alberto Rodríguez-Matías; Roberto Jairo Tuesca Armijos

La generación denomina millennials, no escapan a ser vulnerables a este problema. A pesar de que son líderes en la irreverencia, ser líderes en propuestas innovadoras, ser líderes en emprendimiento, no liderizan en conocimiento sobre enfermedades de transmisión sexual. Conocen profundamente, y lo toman como prioritario, el VIH como enfermedad mortal entre personas que no se cuidan sexualmente, pero lamentablemente otros tipos de enfermedades, $\mathrm{y}$ sobre todo el VPH, no tienen el interés en el colectivo porque no poseen la información suficiente haciéndola una enfermedad silenciosa y prácticamente un rumor de pasillo sin tomarla como fundamental para el desarrollo de la salud y de la vida. Por lo tanto, el VPH, su causa, diagnóstico y terapia, siguen siendo un tema tabú en nuestra sociedad.

\section{Método}

Esta investigación se basó en el análisis y comprensión de las enfermedades de transmisión sexual, en especial el VPH, sobre los jóvenes. Como influye la familia, la sociedad y su entorno en el comportamiento sexual del individuo. La vinculación de las relaciones románticas y las relaciones sexuales a temprana edad. Las necesidades biológicas a estas edades generan vulnerabilidad ante los riesgos de contraer enfermedades. Como los estereotipos generan inhibición en los adolescentes para adquirir preservativos como mecanismo de defensa. Todos estos aspectos influyen directamente en el comportamiento del individuo ante el acto sexual es por ello que es importante conocer los sistemas y medios de protección sexual.

La metodología se basó en técnicas basadas en revisión de textos, documentos y artículos científicos publicados disponibles en la web. Aunado a esto también se aplicaron entrevistas a 


\section{EI VPH: Enemigo silencioso de los millennials}

Vol. 2, núm. 3., (2018)

Venus Alexandra Rodríguez-Matías; Carlos Alfredo Lozano-Rodríguez; Luis Alberto Rodríguez-Matías; Roberto Jairo Tuesca Armijos

miembros de la sociedad, en especial a los millennials, para conocer cuáles son los factores que pueden impulsar el desarrollo participativo de la investigación.

\section{Resultados}

La familia es un factor importante en el comportamiento del individuo. Es el núcleo familiar el principal agente educador y formador, esto desemboca en el comportamiento y racionalidad de las personas, pero este factor importante ha cambiado durante los últimos años. Cambios profundos y convulsivos de estos últimos años han modificado el concepto de familia ya que parecen numerosos modelos que alteran los parámetros con los que se entendía la vida familiar (Valdivia, 2008).

La multiconceptualidad de la familia tiene muchos factores a las cuales se debe su origen, desde su estructura, su funcionamiento hasta su educación. Las mayorías de las familias actuales son monoparentales haciendo influir, directa o indirectamente, en la conducta del individuo. Las opiniones de la madre-padre siembran valores las cuales serán cosechadas a un futuro. Un aspecto fundamental, y que ha crecido de manera rápida ha sido el concepto de género. El género fue un término propuesto por quienes afirmaban que el saber de las mujeres transformaría fundamentalmente los paradigmas de la disciplina (Scott, 1996). Es allí donde radican muchos términos que se debaten hoy en día, y este término de género es la bandera del movimiento de feministas, como por ejemplo.

Estas formaciones de los nuevos núcleos familiares rompen con conceptos clásicos como el de relaciones. Este concepto clásico de relaciones se refiere a instituciones de género encargadas de reproducirnos como mujeres y como hombres. La pareja es una institución de 


\section{EI VPH: Enemigo silencioso de los millennials}

Vol. 2, núm. 3., (2018)

Venus Alexandra Rodríguez-Matías; Carlos Alfredo Lozano-Rodríguez; Luis Alberto Rodríguez-Matías; Roberto Jairo Tuesca Armijos

género de la que no nos percatamos. Es una institución que tiene, entre otras finalidades, la reproducción del hombre y del género (Lagarde, 1990).

Ahora, las relaciones actuales involucran diversidad de género, personas y conductas. Uno de los pilares fundamentales de estas relaciones es que existe interés entre la satisfacción sexual, la ansiedad, algunas prácticas sexuales y las variables sociodemográficas las cuales están relacionadas con el comportamiento sexual (Rodríguez, 2010).

Estas variables que alteran las relaciones son más acentuadas en ciertas edades del individuo. La edad al cual es más vulnerable a muchos factores es la adolescencia ya que su conducta y comportamiento está en función de la relación afectiva que tenga con los padres, es decir con la familia. Es la etapa donde las relaciones románticas se encuentran con las relaciones sexuales. Lamentablemente en la gran mayoría de nuestras sociedades, y hasta del punto de vista cultural, ambas relaciones no pueden completarse mutuamente. Por lo tanto, las relaciones sexuales son totalmente inversas a las relaciones románticas haciendo entonces que la primera esta dominada por necesidades biológicas por lo cual tienden a ser realizadas sin tanta premeditación.

Muchas de estas conductas adolescentes ante las relaciones sexuales se ven involucradas a factores socioculturales y económicos. Muchas de las jóvenes a temprana edad confunden esas relaciones sexuales con relaciones románticas haciéndolas vulnerables a personas que si tienen por objetivo solo satisfacer sus necesidades biológicas, como se muestra la Tabla 1. Esta vulnerabilidad permite creer que la otra persona le transmite seguridad a través del poder de las palabras, pues éstas transmiten amenazas de abandono y desamor que no pueden resistir. El 


\section{EI VPH: Enemigo silencioso de los millennials}

Vol. 2, núm. 3., (2018)

Venus Alexandra Rodríguez-Matías; Carlos Alfredo Lozano-Rodríguez; Luis Alberto

Rodríguez-Matías; Roberto Jairo Tuesca Armijos

poder de esas palabras se relaciona con el temor de no poder realizar un proyecto de vida basado en el matrimonio y la maternidad. Pero, el temor al abandono también proviene de una necesidad afectiva difusa, cuya satisfacción se deposita en ese varón (Pantelides y Geldstein, 1998).

\section{Tabla 1: Distribución de los estudiantes de acuerdo con la edad de la primera relación} sexual según sexo.

\begin{tabular}{lcc}
\hline $\begin{array}{l}\text { Años de la primera } \\
\text { relación sexual }\end{array}$ & Sexenino & \\
\hline 10 & & Masculino \\
\hline 1 & - & 9 \\
12 & 2 & 16 \\
13 & 4 & 18 \\
14 & 8 & 24 \\
15 & 22 & 16 \\
16 & 16 & 3 \\
17 & 10 & 4 \\
18 & 4 & 2 \\
19 & 4 & 0 \\
20 & 1 & - \\
21 & 1 & 1 \\
23 & 1 & - \\
Media & 15,8 & 13,4 \\
\hline
\end{tabular}

Fuente: (García, Álvarez y Lozano, 2001)

Un catalizador de esta vulnerabilidad de las adolescentes es el papel que juega la televisión ya que la mayoría de ellos solo visualiza programas de alto contenido romántico y sexual haciendo entonces que, a mayor exposición a programas con contenido romántico, más favorable es la actitud personal hacia las relaciones sexuales en la adolescencia (Vargas, Barrera, Burgos y Daza, 2006).

Se genera un desconocimiento entre los adolescentes cuando desean iniciar precozmente las relaciones sexuales y es sobre los métodos anticonceptivos al igual que sobre las infecciones 


\section{EI VPH: Enemigo silencioso de los millennials}

Vol. 2, núm. 3., (2018)

Venus Alexandra Rodríguez-Matías; Carlos Alfredo Lozano-Rodríguez; Luis Alberto Rodríguez-Matías; Roberto Jairo Tuesca Armijos

de transmisión sexual. El primero está relacionado directamente a un embarazo precoz que afecta su situación emocional, parental y socioeconómica, aunado a esto con un alto riesgo medico produciendo morbimortalidad materna y un aumento estimado de 2 a 3 veces en la mortalidad infantil, cuando se compara con los grupos de edades entre 20 y 29 años (Menéndez, Cabrera, Rodríguez y Castellanos, 2012). El segundo considerado el más grave de los problemas.

Las enfermedades de transmisión sexual (E.T.S.) son un grupo de enfermedades transmisibles que se adquieren fundamentalmente por contacto sexual y constituyen probablemente el grupo de patologías caracterizado por producirse fundamentalmente en grupos de población cada vez más jóvenes y del sexo femenino(García, Álvarez y Lozano, 2001). La Figura 1 se detalla la distribución de la sífilis por edad y sexo para el año 1991.

Figura 1: Distribución de la sífilis por edad y sexo en la población de Valladolid, España

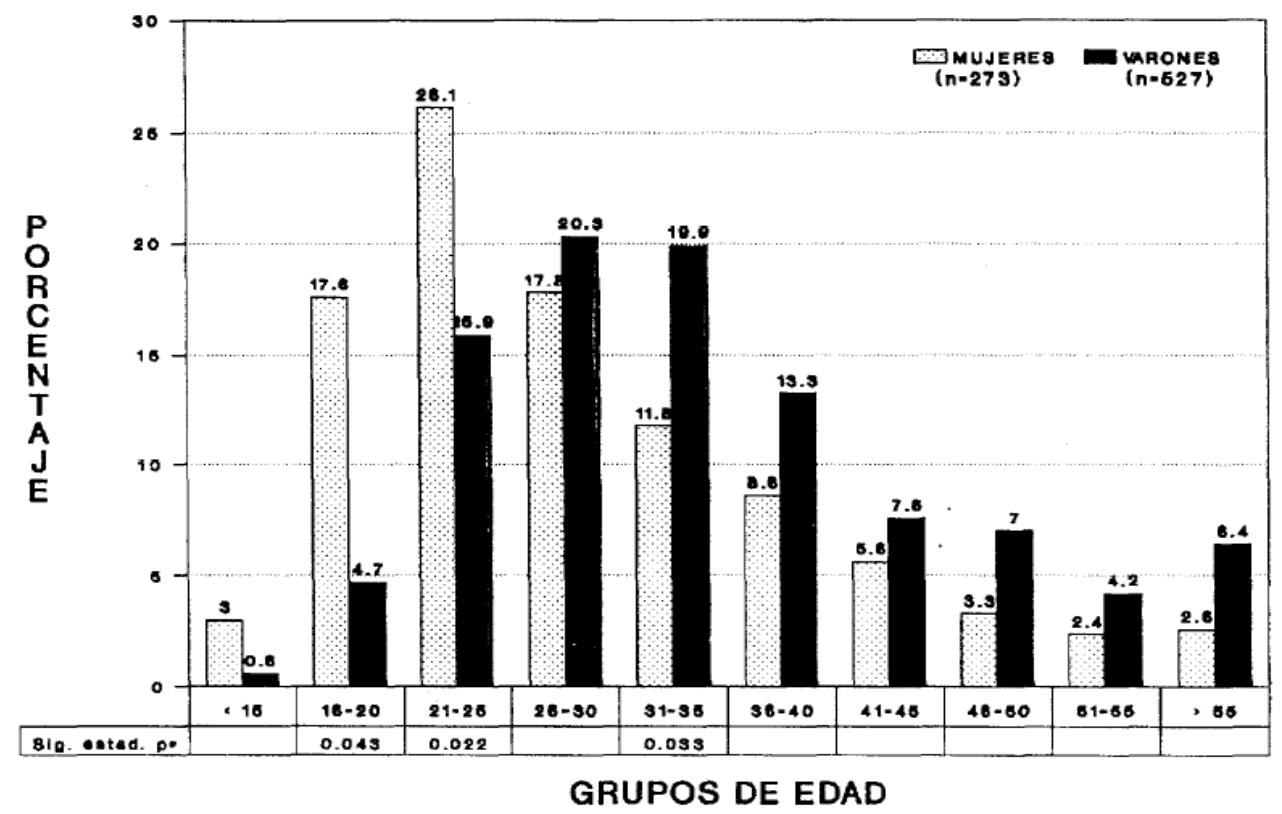

.Fuente: (Orduiia, y otros, 1991). 


\section{EI VPH: Enemigo silencioso de los millennials}

Vol. 2, núm. 3., (2018)

Venus Alexandra Rodríguez-Matías; Carlos Alfredo Lozano-Rodríguez; Luis Alberto

Rodríguez-Matías; Roberto Jairo Tuesca Armijos

Se observa como la población femenina entre los 15 a 25 años es vulnerable a enfermedades de transmisión sexual como la sífilis. Estos mismos porcentajes se extrapolan para los otros tipos de enfermedades. Indistintamente del género, las ETS depende de variables fundamentales como el comportamiento sexual y actitud entre los adolescentes, tal cual se muestra en la Tabla 2.

\section{Tabla 2: Antecedentes de ETS, comportamientos y actitudes sexuales riesgosas de los} adolescentes en cada tipo de enseñanza



Fuente:(Cortés, García, Hernández, Monterrey y Fuentes, 1999)

Una de la ETS que ha aumentado en los últimos años es el virus del papiloma humano, VPH. La incidencia en el mundo aproximadamente es $10 \%$ y durante toda la vida el riesgo de exposición a la infección es de un 50 a 80\%, esto varía de acuerdo a edad, localización geográfica y la frecuencia de tamizaje. Se conoce que para que se dé la trasmisión del VPH debe haber contacto sexual con la piel genital, mucosas o líquidos corporales de una pareja con lesiones verrucosas o con infección subclínica (Alfaro y Fournier, 2013).

El desarrollo del VPH tiene factores importantes y diversos entre los cuales están las relaciones sexuales tempranas y la promiscuidad. Es aquí donde los adolescentes están indefensos ya que la mayoría solo requiere garantizar sus necesidades biológicas por lo cual tienden a aplicar promiscuidad aumentando así el riesgo de contraer el VPH. Los jóvenes desconocen sobre el VPH y algunas de sus características. La Tabla 3 se detalla un cuestionario realizado a una población adolescente sobre el VPH, lo quemás llama la atención es que hay 


\section{EI VPH: Enemigo silencioso de los millennials}

Vol. 2, núm. 3., (2018)

Venus Alexandra Rodríguez-Matías; Carlos Alfredo Lozano-Rodríguez; Luis Alberto Rodríguez-Matías; Roberto Jairo Tuesca Armijos

rubros en los que el $50 \%$ conoce y el otro $50 \%$ no. Se observa que desconocen ciertosfactores de riesgo(Contreras, y otros, 2017).

Contraer este virus afecta considerablemente el desarrollo profesional y personal de los jóvenes a futuro. Esta generación millennials son parte fundamental de nuestra sociedad y resaltan por sus características. Los millennials son jóvenes nacidos y educados en ambientes altamente tecnológicos, con una fuerte cultura cliente-servicio. En consonancia con ello, consideran que la educación es una mercancía para ser adquirida y consumida. Por eso esperan que su acercamiento al conocimiento sea lo más rápido, entretenido y sencillo posible. Los millennials poseen escasa habilidad para resolver problemas, para seguir una argumentación o una demostración. Presentan, además, dificultades para planificar a largo plazo (Cuesta, Ibáñez, Tagliabue y Zangaro, 2008). Por lo tanto, todas estas características concuerdan con una falta de interés en la educación sexual y por ende se incremente el contagio a ETS.

Tabla 2: Antecedentes de ETS, comportamientos y actitudes sexuales riesgosas de los adolescentes en cada tipo de enseñanza

\begin{tabular}{lll}
\hline Preguntas & \multicolumn{2}{c}{ Respuestas (\%) } \\
\cline { 2 - 3 } & Correctas & Incorrectas \\
\hline Definición VPH & 35.5 & 64.6 \\
Posible factor de VPH & 78.5 & 21.5 \\
¿Cuál es la causa de todos los casos de cáncer cervicouterino? & 52.9 & 47.1 \\
¿Qué detecta la prueba del Papanicolaou? & 72.3 & 27.7 \\
Se sabe que el VPH puede generar... & 31.4 & 68.6 \\
La infección por VPH genera en el hombre... & 87.7 & $91.3 \%$ \\
La infección por VPH se da por: & 82.6 & 12.4 \\
Este método anticonceptivo protege contra el VPH & 57.9 & 17.4 \\
Son posibles factores de riesgo para VPH el sexo anal y oral & 32.6 & 42.1 \\
El VPH se contagia de la mujer hacia el hombre & 51.2 & 67.4 \\
La mujer es la portadora del VPH & 58.7 & 48.8 \\
El inicio de la vida sexual activa es un factor de riesgo para adquirir VPH & 12.0 & 41.3 \\
En el caso de las mujeres, fumar puede ser un riesgo para adquirir VPH & 56.6 & 88.0 \\
El VPH se presenta en población de bajos recursos económicos & 57.0 & 43.4 \\
El inicio de la vida sexual activa a temprana edad, es un factor de riesgo causal & 59.1 & 43.0 \\
La vacuna contra el VPH protege contra todos los tipos de virus & 75.2 & 40.9 \\
Los hombres están protegidos contra el VPH & 49.2 & 24.5 \\
La vacuna contra el VPH es solo para mujeres & 24.4 & 50.8 \\
La vacuna de VPH se aplica a los bebés de ambos sexos al nacer & 16.9 & 75.6 \\
Existen más de 100 tipos de VPH & & 83.1 \\
\hline
\end{tabular}

Fuente:(Contreras, y otros, 2017).

Revista Científica Mundo de la Investigación y el Conocimiento. 2 (3). pp. 393-409 


\section{El VPH: Enemigo silencioso de los millennials}

Vol. 2, núm. 3., (2018)

Venus Alexandra Rodríguez-Matías; Carlos Alfredo Lozano-Rodríguez; Luis Alberto Rodríguez-Matías; Roberto Jairo Tuesca Armijos

Es por ello, que es necesario fomentar el conocimiento de las manifestaciones clínicas elementales del VPH u otras ETS, desde la familia y centros educativos a fin de que puedan prevenirlas para que no adquieran esos conocimientos a partir de la experiencia personal de haber adquirido el virus ya que los jóvenes que han sufrido este mal son capaces de reconocer más y mejor las diferentes manifestaciones clínicas de esas infecciones, y de esta manera, transmiten esos conocimientos a sus congéneres(Álvarez, Domínguez y De la Torre, 2014).

\section{Discusión y conclusiones}

La familia es la parte fundamental para el desarrollo de las sociedades. Es génesis del comportamiento de los individuos a lo largo de la vida. En la actualidad las sociedades estas conformadas por múltiples manifestaciones culturales y sociales. Una de las manifestaciones es la sexualidad, generando múltiples matices que han surgido en cada espacio y tiempo. La sexualidad viene cargada de muchos temas que son considerados mitos y tabú para la gran mayoría de los individuos. La sexualidad depende del individuo que lo practique. Para los hombres es de carácter casi viril ser el que propone la relación sexual ya que su entorno se lo exige y más si su papel es el de procrear y ser el sostén de la familia. En cambio, las mujeres tienden a ser procreadoras, cuidar a los hijos y satisfacer los deseos sexuales de los hombres. Es aquí donde entra las relaciones románticas y las relaciones sexuales en el género, las primeras son impartidas desde su infancia buscando garantizar las necesidades básicas de supervivencia en cambio las segundas son para garantizar las necesidades biológicas. Desde corta edad, la familia les inculca los valores de las relaciones románticas, en cambio dentro de ellas surge explorar sus deseos biológicos que se contrapone a los dictámenes de la sociedad. Un factor importante para 


\section{EI VPH: Enemigo silencioso de los millennials}

Vol. 2, núm. 3., (2018)

Venus Alexandra Rodríguez-Matías; Carlos Alfredo Lozano-Rodríguez; Luis Alberto Rodríguez-Matías; Roberto Jairo Tuesca Armijos

el crecimiento de este tipo de relaciones ha tenido los medios de comunicación ocasionando que crezcan exponencialmente sus contactos sexuales.

Estas conductas sexuales son más vulnerables desde temprana edad haciendo que surjan riesgos en el individuo. El inicio precoz de las relaciones sexuales parece estar relacionado directamente con un mayor número de embarazos no deseados y de infecciones de transmisión sexual. Es por ello que los adolescentes son más vulnerables a este tipo de riesgos. La tendencia a la liberación sexual en los jóvenes se manifiesta en un aumento de parejas sexuales y la inestabilidad en estas los cuales los hacen propensos a sufrir enfermedades sexuales. Por lo cual, las ETS representan a un grupo de padecimientos infecciosos que se transmiten predominantemente por contacto sexual. Es por ello que los adolescentes son considerados de alto riesgo para contraer estas enfermedades ya que tienen relaciones sexuales sin ningún medio de protección, son biológicamente más susceptibles a la infección, son más renuentes a solicitar consulta médica debido a que enfrentan múltiples obstáculos para utilizar los servicios de atención médica y no son sujetos de vigilancia epidemiológica en pareja (Calderón, 1999).

Una de estas enfermedades es el VPH. Considerada como la ETS más común en el mundo que afecta a mujeres y hombres de cualquier edad. Existen dos grupos de infección: los tipos de bajo riesgo que suelen causar verrugas genitales o infección subclínica, y los tipos de alto riesgo V.P.H 16 y 18 más comunes que progresan a cáncer cervicouterino. Como se conoce, el sistema inmune se encarga de aclarar o limpiar la mayoría de las infecciones por este virus, pero en algunos casos no logra deshacerse del mismo, es aquí donde es de mayor importancia la prevención con la vacunación y diagnóstico temprano (Alfaro y Fournier, 2013). 


\section{EI VPH: Enemigo silencioso de los millennials}

Vol. 2, núm. 3., (2018)

Venus Alexandra Rodríguez-Matías; Carlos Alfredo Lozano-Rodríguez; Luis Alberto Rodríguez-Matías; Roberto Jairo Tuesca Armijos

Es por ello que los adolescentes llamados actualmente millennials no escapan a este problema. Esta cultura predomina la solución rápida a los problemas, privilegian los horarios flexibles y el tiempo libre por ende no les gustan las responsabilidades. Son fieles a sí mismos es decir a sus creencias por lo cual tienen preconcebida su conducta sexual pues rara vez la cambian. Todas estas características pueden acelerar el riesgo de contraer el virus. Por lo tanto, se puede considerar que el VPH puede ser un enemigo silencioso en su vida cotidiana.

Para evitar sufrir de esta enfermedad, como de otras ETS, se consideran estos aspectos que van a disminuir su riesgo:

- El valor de la familia es fundamental para desarrollar un individuo que promueva la autonomía y la vinculación. La primera incluye las exigencias de madurez, el razonamiento inductivo y la apertura a la experiencia. Las segundas, la comunicación abierta y confiada, la expresión del afecto y el disfrute de momentos de cercanía e intimidad.

- Potenciar el desarrollo de la educación sexual en los hogares y centros educativos con la finalidad que la información llegue a todos los individuos independientemente de los medios que se utilicen.

- Que se utilicen los medios de protección como los preservativos. Que sean accesibles para los jóvenes y sobre todo que las mujeres empiecen a llevarlos dentro de sus productos de aseo personal.

- Cambiar la orientación actual de las campañas publicitarias de los medios de comunicación. Que dentro de estos se creen programas de orientación sexual. Que los 


\section{El VPH: Enemigo silencioso de los millennials}

Vol. 2, núm. 3., (2018)

Venus Alexandra Rodríguez-Matías; Carlos Alfredo Lozano-Rodríguez; Luis Alberto Rodríguez-Matías; Roberto Jairo Tuesca Armijos

mismos adolescentes sean los protagonistas de esta comunicación y no un simple consumidor.

- Contrarrestar las actitudes y comportamientos de los adultos a los temas sobre sexualidad ya que sus opiniones pueden influir negativamente a que el joven no adquiera preservativos.

\section{Bibliografía}

Alfaro, A., \& Fournier, M. (2013). Virus del papiloma humano. Revista médica de Costa Rica y Centroamerica, 606: 211-217.

Álvarez, M., Domínguez, J., \& De la Torre, L. (2014). Factores relacionados con el contagio de las infecciones de transmisión sexual en la adolescencia. Revista Habanera de Ciencias Médicas, 13(2): 270-283.

Calderón, E. (1999). Tratamiento y prevención de las enfermedades de transmisión sexual. Salud pública de México, 41(4): 334-343.

Concha, M. (2007). Diagnóstico y terapia del virus papiloma humano. Infectología Práctica Pontificia Universidad Católica de Chile, 209-214.

Contreras, R., Santanab, A., Jiménez, E., Gallegos, R., Xeque, A., Palomé, G., y otros. (2017). Nivel de conocimientos en adolescentes sobre el virus del papiloma humano. Enfermería Universitaria, 14(2): 104-110.

Cortés, A., García, R., Hernández, M., Monterrey, P., \& Fuentes, J. (1999). Encuesta sobre comportamientos sexuales riesgosos y enfermedades de transmisión sexual en estudiantes adolescentes de Ciudad de La Habana, 1996. Revista cubana de medicina tropical, 120124.

Cuesta, E., Ibáñez, E., Tagliabue, R., \& Zangaro, M. (2008). El impacto de la generación millennial en la universidad: un estudio exploratorio. Acta Académica, 200-208.

García, C., Álvarez, V., \& Lozano, M. (2001). ¿Qué saben nuestros estudiantes acerca de las enfermedades de transmisión sexual? Revista cubana de higiene y epidemiología, 47-51.

Lagarde, M. (1990). La multidimensionalidad de la categoría género y del feminismo. Ciudad de México: CESU-UNAM. 


\section{EI VPH: Enemigo silencioso de los millennials}

Vol. 2, núm. 3., (2018)

Venus Alexandra Rodríguez-Matías; Carlos Alfredo Lozano-Rodríguez; Luis Alberto

Rodríguez-Matías; Roberto Jairo Tuesca Armijos

León, G., \& Bosques, O. (2018). Infección por el VPH y factores relacionados con la actividad sexual en la génesis del cuello uterino. Instituto Nacional de Radiología y Oncología. Recuperado de: http://www.bvs.sld.cu/revistas/gin/vol31_1_05/gin10105.htm

Menéndez, G., Cabrera, I., Rodríguez, Y., \& Castellanos, J. (2012). El embarazo y sus complicaciones en la madre adolescente. Revista Cubana de Obstetricia y Ginecología, 333-342.

Orduiia, D., Chu, J., Eiros, J., Bratos, M., Gutiérrez, M., Almaraz, A., y otros. (1991). Distribucion por edad y sexo de las enfermedades de transmisión sexual en Valladolid. Estudio de 5.076 casos. Revista de higiene pública, 247-258.

Pantelides, E., \& Geldstein, R. (1998). Encantadas, convencidas o forzadas: iniciacion sexual en adolescentes de bajos recursos. Centro de Estudios de Población - CENEP, 1-6.

Rodríguez, o. (2010). Relación entre satisfacción sexual, ansiedad y prácticas sexuales. Pensamiento Psicológico, 41-52.

Scott, J. (1996). El género: una categoría útil para el análisis histórico. Ciudad de México: Lamas Marta Compiladora.

Valdivia, C. (2008). La familia: concepto, cambios y nuevos modelos. La Revue du Redif Universidad de Deust, 15-22.

Vargas, E., Barrera, F., Burgos, M., \& Daza, B. (2006). La intención de los jóvenes de tener relaciones sexuales en la adolescencia: el papel de la televisión, la relación con los padres y las cogniciones. Universitas Psychologica, 69-84. 